\title{
PRODUCTION OF MYCOTOXINS BY GALACTOSE OXIDASE PRODUCING FUSARIUM USING DIFFERENT CULTURE MEDIA
}

\author{
Angela Maria Pereira; Carlos Kemmelmeier* \\ Departamento de Bioquímica, Universidade Estadual de Maringá, Maringá, PR, Brasil \\ Submitted: July 27, 1999; Returned to authors for correction: October 08, 1999; Approved: April 20, 2000
}

\begin{abstract}
The original isolate of the galactose oxidase producing fungus Dactylium dendroides, and other five galactose oxidase producing Fusarium isolates were cultivated in different media and conditions, in order to evaluate the production of 11 mycotoxins, which are characteristic of the genus Fusarium: moniliformin, fusaric acid, deoxynivalenol, fusarenone-X, nivalenol, 3-acetyldeoxynivalenol, neosolaniol, zearalenol, zearalenone, acetyl T-2, and iso T-2. The toxicity of the culture extracts to Artemia salina larvae was tested.
\end{abstract}

Key words: Galactose oxidase, Fusarium, Dactylium dendroides, mycotoxins

\section{INTRODUCTION}

Galactose oxidase (EC 1.1.3.9) is a fungal enzyme secreted by Dactylium dendroides (3), Gibberella fujikuroi (1), Fusarium graminearum $(7,11)$ and Fusarium moniliforme $(13)$. This enzyme catalyses oxidation of D-galactose to galactohexodialdose, which reduces molecular oxygen to hydrogen peroxide, and has been used for the specific determination of D-galactose (2).

The first fungus capable to produce galactose oxidase was isolated in Curitiba, Brazil, in 1955, and classified as Polyporus circinatus (9). This classification was questioned by Nobles and Madhosingh (25), who considered that this fungus was Dactylium dendroides, the conidial form of Hypomyces rosellus, a parasite of mushroom cultures. Despite the controversy concerning the taxonomic identification of the Galactose Oxidase Producing Fungus (GOPF) and the efforts made by Kemmelmeier and Zancan for its identification $(17,18,19,20,27)$, a taxonomic classification has not yet been achieved. Ögel et al. (26) were the first to report its sporulation. They also compared the DNA sequences of the galactose oxidase gene regions of Cladobotrium dendroides and of the fungus. They mentioned some resemblance between the conidia and conidiophores of $F$. chlamydosporum and GOPF, in addition to data shown by Fusarium of Arthrosporiella section, described by Booth (5). According to data reported by Ögel et al. (26), the fungus isolated in Curitiba was re-identified as belonging to the genus Fusarium.

Taking into account the importance of Fusarium in agriculture and health due to mycotoxins production (21), the present work aimed to correlate mycotoxins production with taxonomy (7). Five samples of galactose oxidase producing Fusarium were compared with GOPF for production of mycotoxins in the following solid substrates: rice (production of trichothecenes), corn (production of moniliformin and trichothecenes), agar (production of fusaric acid) and liquid medium (production of galactose oxidase) (22) and on the conditions described for the production of 3acetyldeoxynivalenol (31). The production of the moniliformin, fusaric acid, 3-acetyldeoxynivalenol (ADON), deoxynivalenol (DON), fusarenone-X (FX), nivalenol (NIV), neosolaniol (NEO), zearalenone (ZEA), zearalenol (ZEOH), iso T-2 and acetyl T-2, typical of Fusarium fungi, was tested. The toxicity of extracts against Artemia salina larvae was also checked.

\section{MATERIALS AND METHODS}

Microorganisms. The following isolates of Fusarium were used: Fusarium graminearum strain IAPAR 2218 (Agronomic Institute of Paraná - PR); F. graminearum strain UEL 2118 R (State University of Londrina - PR, kindly offered by Dr. Elisa

\footnotetext{
* Corresponding author. Mailing address: Universidade Estadual de Maringá, Departamento de Bioquímica, Av. Colombo, 5790, CEP 87020-900. Maringá, PR, Brasil. Fax: (+5544) 263-3655. E-mail: ckemmelmeier@uem.br
} 
Yoko Hirooka) F. graminearum strain UnB 1269 (University of Brasília - DF); F. moniliforme var. subglutinans strain UnB 379; F. acuminatum strain UnB 356, and Dactylium dendroides. The original galactose oxidase producer strain (GOPF), isolated in Curitiba, was kindly provided by Dr. Glaci T. Zancan. These isolates were stored at the Laboratory of Chemistry and Physiology of Microorganisms of the Department of Biochemistry of the State University of Maringá - PR.

Growth rate, morphology and pigmentation. For comparisons of growth rate, morphology and pigmentation, fungi were initially cultured for four days at $25^{\circ} \mathrm{C}$ in Potato Dextrose Agar (PDA), transfered in triplicate to Petri dishes and incubated under the same conditions. The growth rate (measured as colony diameter), morphology and pigmentation (colour) of the colonies were observed during four days, as described by Booth (5).

General conditions of growth for the production and extraction of mycotoxins. Growth of fungi and testing for mycotoxins were done as follows:

Moniliformin. The fungi were activated in PDA for 10 days, at $25^{\circ} \mathrm{C}$, and them transferred to corn medium $(40 \mathrm{~g}$ of corn kernels and $40 \mathrm{ml}$ of water), previously autoclaved for one hour in two consecutive days, and incubated for 21 days at $25^{\circ} \mathrm{C}$. The culture was lyophilized, fragmented in a mortar and the resulting powder stored at $5^{\circ} \mathrm{C}$. The moniliformin assay was carried out mixing 10 grams of the powder with $100 \mathrm{ml}$ of chloroform and agitating at $28^{\circ} \mathrm{C}$ for 48 hours in orbital shaker (121 rev. $\mathrm{min}^{-1}$ ). Chloroform was removed by filtration and 100 $\mathrm{ml}$ of methanol/water $(80: 20, \mathrm{v} / \mathrm{v})$ was added and shaked again for 48 hours. The extracts were combined and dried in a rotary evaporator, suspended in $2 \mathrm{ml}$ methanol, divided in two aliquots of $1 \mathrm{ml}$ and stored at $5^{\circ} \mathrm{C}$, in the dark, until use.

Fusaric acid. Richard's medium and the conditions described by Davis (10) were used. After growth for 14 days at $28^{\circ} \mathrm{C}$, the cultures were placed in freezer at $-15^{\circ} \mathrm{C}$ for 48 hours prior to extraction. Then, the agar was heated in a microwave oven and the mycelium mass was removed with tweezers. The agar was acidified to $\mathrm{pH} 4.0$ and extracted three times with 10 $\mathrm{ml}$ of ethyl acetate, combined and concentrated in a vacuum rotary evaporator until drying. Residues were suspended in 2 $\mathrm{ml}$ of ethyl acetate and stored under refrigeration.

Trichothecenes. Trichothecenes were investigated using the conditions describeb by Silva (30). Fungi were activated in PDA and then transferred to rice. Ten grams of rice grains were horizontally placed in a $70 \mathrm{ml}$ tube, added with water to obtain $40 \%$ of initial humidity. Tubes were autoclaved twice at $121^{\circ} \mathrm{C}$ in two consecutive days. The tubes were inoculated with the fungi, and incubated for 21 days at $25^{\circ} \mathrm{C}$. Each culture was extracted adding $50 \mathrm{ml}$ of ethyl acetate and remained at room temperature during 12 hours. The organic extract of each tube was recovered by filtration. After extraction with ethyl acetate, the residue was extracted again with $50 \mathrm{ml}$ of methanol/water $(6: 4, \mathrm{v} / \mathrm{v})$ under the same conditions. The extract was recovered by filtration and combined with the previous extract, treated with anhydrous sodium sulphate and concentrated. The residue was dissolved in $2 \mathrm{ml}$ of benzene/acetone $(2: 1, \mathrm{v} / \mathrm{v})$ and passed through a column (Pasteur pipettes $10 \times 1 \mathrm{~cm}$ ) containing $7 \mathrm{ml}$ of silica gel. The columns were washed with $20 \mathrm{ml}$ of benzene to remove lipids and then eluted with $20 \mathrm{ml}$ of benzene/acetone $(1: 1, \mathrm{v} / \mathrm{v})$. Eluates were concentrated and the residues suspended in $2 \mathrm{ml}$ of acetone and stored for further analyses.

ADON production in liquid medium. Production of ADON was tested in liquid medium (31). The PDA activated fungi were inoculated in $250 \mathrm{ml}$ of YPS medium (yeast extract, peptone and sucrose) and incubated in orbital shaker at $150 \mathrm{rev} \cdot \mathrm{min}^{-1}$, $25^{\circ} \mathrm{C}$, for 48 hours. Aliquots of $0.2 \mathrm{ml}$ of mycelium suspensions were inoculated in $25 \mathrm{ml}$ of Modified Minimum Medium (MMM) and incubated at $25^{\circ} \mathrm{C}$ for 72 hours. Cultures were filtered and filtrates were extracted three times with $10 \mathrm{ml}$ of ethyl acetate. The organic extracts combined, passed through anhydrous sodium sulphate, and evaporated until dryness. Residues were suspended in $2 \mathrm{ml}$ of acetonitrile and stored for further analyses.

Production of metabolites on Markus medium. For evaluation of the production of metabolites in Markus medium, the culture conditions described for the production of galactose oxidase (22) were used. The extraction procedure was identical to that described for ADON.

Qualitative analyses. Thin layer chromatography (TLC) was performed with 5 to $10 \mu \mathrm{l}$ of each fungal culture extract. The extracts were applied to $20 \times 20 \mathrm{~cm}$ Silica gel plates $(250 \mu \mathrm{m}$ layer thickness - Sigma Co.), along with specific standards or a pool of standards (Sigma Co.). Plates were developed and visualised under different conditions. For the assay of moniliformin, butanol/acetic acid/water $(4: 1: 5, \mathrm{v} / \mathrm{v})$ and chloroform/methanol (4:3, v/v) were used as solvents, and 2,4dinitrophenylhydrazine/sulphuric acid/methanol $(0.5 \mathrm{~g}: 1 \mathrm{ml}: 25$ $\mathrm{ml}, \mathrm{w} / \mathrm{v} / \mathrm{v}$ ) as visualisation reagent. For trichothecenes, chloroform/methanol $(97: 3, \mathrm{v} / \mathrm{v})$ was employed as solvent and the procedure described by Kamimura (16) was used for visualisation. Fusaric acid was developed with butanol/acetic $\mathrm{acid} /$ water $(4: 1: 1, \mathrm{v} / \mathrm{v})$, and visualised with copper acetate and bromophenol. ADON was visualized by $20 \%$ aluminium chloride, after developing with ethyl acetate/toluene $(3: 1, \mathrm{v} / \mathrm{v})$.

Quantitative analyses. A Gas-liquid chromatograph (CG 35370), equipped with flame ionization detector (FID), was employed with QF-1 column (2 mm internal diameter and 180 $\mathrm{cm}$ length). Temperatures of the injector and the detector were $280^{\circ} \mathrm{C}$ and $300^{\circ} \mathrm{C}$, respectively. The initial temperature of the column $\left(180^{\circ} \mathrm{C}\right)$ was manually adjusted in $40^{\circ} \mathrm{C}$ every five minutes until reaching $250^{\circ} \mathrm{C}$. Flow rates were $70 \mathrm{ml} \cdot \mathrm{min}^{-1}$ for Nitrogen, $200 \mathrm{ml} \cdot \mathrm{min}^{-1}$ for Oxygen and $92 \mathrm{ml} \cdot \mathrm{min}^{-1}$ for Hydrogen. Aliquots of $0.5 \mathrm{ml}$ of each extract in tubes were evaporated under nitrogen atmosphere, and added with $80 \mu \mathrm{l}$ of the silylating agent Tri-sil/TBT with special formulation v/v of 
TMS-Imidazole (Pierce Chemical Co.). The tubes were closed and heated at $60^{\circ} \mathrm{C}$ for 15 minutes. After cooling, $3 \mu \mathrm{l}$ of the samples were injected into the chromatograph. For quantifying, triangulation system was used against known concentrations of standards. The retention time for each standard of secondary metabolite was initially obtained individually and also as a pool of standards.

Artemia salina larvae test. Larvae of Artemia salina (24 hours after egg rupture) were obtained as described by Harwig (15) and Eppley (12). For the toxicity test, 25, 50, 75 and 100 $\mu \mathrm{l}$ of each extract and controls (saline and dilution solvent) were placed in tubes, in triplicate. A number of larvae ranging from 8 to 15 per $0.5 \mathrm{ml}$ of saline were transferred to the tubes containing the extracts. After 16 hours, larvae were counted. Larvae not swimming forward were considered dead (even if exhibited motion). Then, chloroform was added to kill viable larvae and another count was carried out. The number of live larvae was calculated by subtraction. Experiments were carried out in three replicates.

\section{RESULTS}

The growth rate of fungi varied from 8.0 to $2.0 \mathrm{~cm}: F$. graminearum strain $2118 \mathrm{R}(8.0 \mathrm{~cm}), F$. graminearum strain $2218(7.8 \mathrm{~cm})$, GOPF $(7.0 \mathrm{~cm})$, F. graminearum strain 1269 $(4.5 \mathrm{~cm})$, F. moniliforme var. subglutinans strain $379(4.3 \mathrm{~cm})$ and $F$. acuminatum strain $356(2.0 \mathrm{~cm})$. The first three strains presented the largest similarity in growth rate and red pigmentation on the back of the colonies. However, the colony aspect of GOPF resembled $F$. graminearum strain 1269.

Only zearalenol (Rf 0.64 ) produced by $F$. graminearum strain 2218 grown in rice could be identified through the TLC analysis of the culture extracts (data not shown). When grown in corn, $F$. graminearum strain 2218 produced zearalenone ( $\mathrm{Rf} 0.83)$, zearalenol ( $\mathrm{Rf} 0.68$ ) and nivalenol (Rf 0.08); F. graminearum strain 1269 produced zearalenol ( $R f$ 0.68), nivalenol ( $R f 0.08$ ) and toxin Iso T-2 (Rf 0.86) and F. acuminatum strain 356 produced zearalenol ( $R f 0.67)$. None of the studied metabolities was detected for strains grown in Markus medium, MMM or Richard medium.

The analysis of mycotoxins by GLC with flame ionization detector and silylated derivatives exhibited some inconveniences, such as deposition of silica on the detector, causing variation in retention times, as described in the literature (7). Despite the precautions, variations of retention times of standards occurred (DON 3.45-5.30; FX 5.30-6.30; NIV 5.456.45; ADON 6.45-8.00; NEO 8.10-10.00; ZEOH 10.35-11.30; ZEA 12.00-12.30; iso T-2 12.30-13.30 and Ac T-2 13.00-14.05). Consequently, retention times were used only as indicatives, since correct determinations could only be achieved through GLC analysis coupled to mass fragmentation. The gas-liquid chromatography analysis of fungal extracts improved the comparison of secondary metabolites produced in different media. Rice and corn were the most effective substrates.

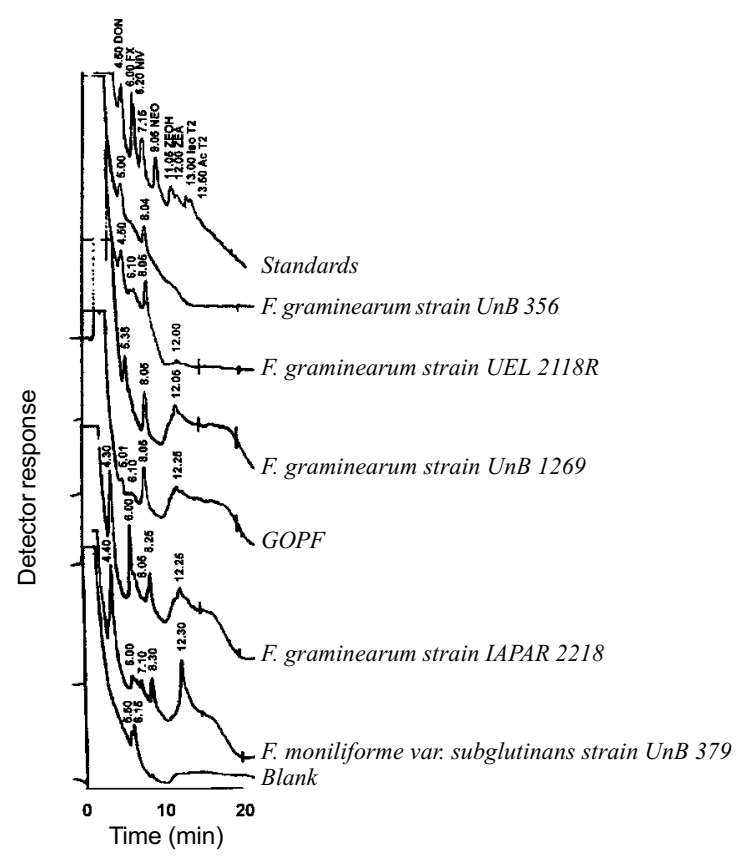

Figure 1. GLC profiles of the pool of mycotoxins and the metabolites produced by the fungi grown on rice $(3 \mu 1-$ Attenuation $1 \mathrm{x})$. Conditions as described in materials and methods.

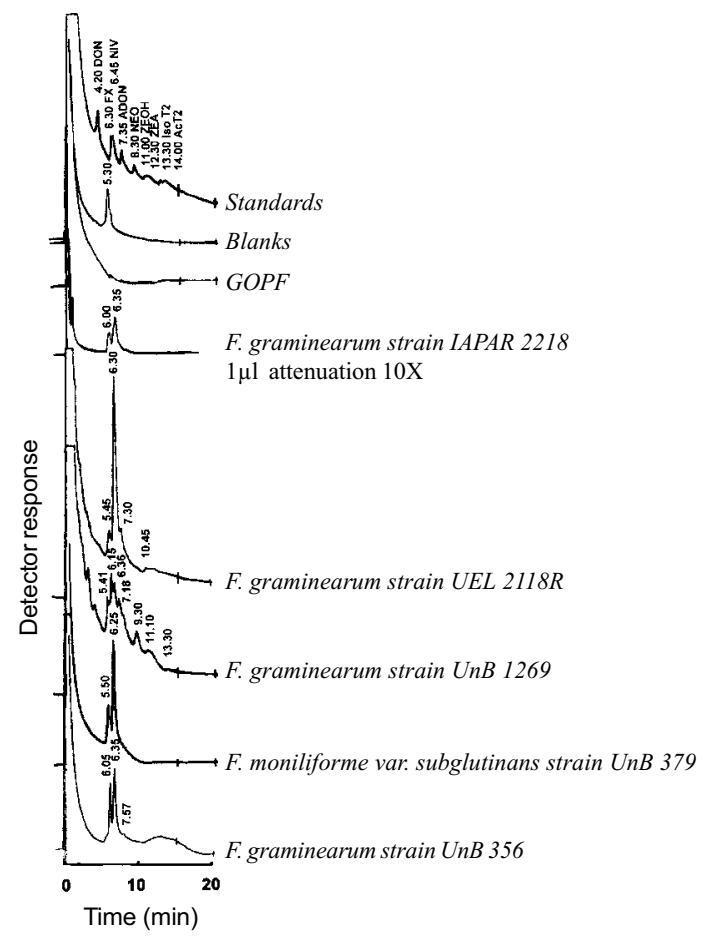

Figure 2. GLC profiles of the pool of mycotoxins and the metabolites produced in corn $(3 \mu \mathrm{l}-$ Attenuation $1 \mathrm{x})$. 
The chromatographic profiles of the extracts of fungi cultured in rice (Fig.1) showed similarities in all studied cases and some sharp defined peaks. Based on the retention times of standards, one can determine the presence of DON and make tentative attributions of ADON. Table 1 shows a quantitative analysis of these components.

Table 4 indicates that the extracts of other culture media (Markus, MMM and Richard) presented toxic effects only when volumes of $100 \mu 1$ were used.

Table 1. Quantitative determination by GLC of DON and ADON produced $(\mu \mathrm{g} / \mathrm{g})$ in rice.

\begin{tabular}{lcc}
\hline Fungi & DON & ADON \\
\hline F. graminearum strain IAPAR 2218 & 4.08 & 2.40 \\
F. graminearum strain UEL 2118 R & 1.32 & 3.04 \\
F. graminearum strain UnB 1269 & 1.20 & 3.68 \\
F. moniliforme & & \\
$\quad$ var. subglutinans strain UnB 379 & 4.90 & 2.47 \\
F. acuminatum strain UnB 356 & 1.38 & 1.16 \\
Galactose oxidase producer fungus & 0.22 & 3.48 \\
\hline
\end{tabular}

Aliquots of the fungi extracts obtained from the different culture media were analysed for the toxicity to Artemia salina larvae. All rice and corn cultures extracts exhibited toxicity (Tables 2 and 3).

Table 2. Effect of the extracts $(\mu 1)$ of rice culture media on the mortality (\%) of Artemia salina larvae.

\begin{tabular}{lcccc}
\hline Fungi & $25 \mu 1$ & $50 \mu 1$ & $75 \mu 1$ & $100 \mu 1$ \\
\hline F. graminearum strain UEL 2118 R & 9 & 10 & 83 & 22 \\
F. graminearum strain IAPAR 2218 & 35 & 66 & 72 & 73 \\
F. graminearum strain UnB 1269 & 14 & 31 & 63 & 67 \\
F. moniliforme & & & & \\
$\quad$ var. subglutinans strain UnB 379 & 0 & 23 & 75 & 75 \\
F. acuminatum strain UnB 356 & 0 & 15 & 38 & 30 \\
Galactose oxidase producer fungus & 14 & 17 & 19 & 23 \\
\hline
\end{tabular}

Table 3. Effect of the extracts $(\mu 1)$ of corn culture on the mortality (\%) of Artemia salina larvae.

\begin{tabular}{lcccc}
\hline Fungi & $25 \mu \mathrm{l}$ & $50 \mu \mathrm{l}$ & $75 \mu \mathrm{l}$ & $100 \mu \mathrm{l}$ \\
\hline F. graminearum strain UEL 2218 R & 14 & 55 & 65 & 100 \\
F. graminearum strain IAPAR 2218 & 11 & 25 & 97 & 100 \\
F. graminearum strain UnB 1269 & 62 & 100 & 100 & 100 \\
F. moniliforme & & & & \\
$\quad$ var. subglutinans strain UnB 379 & 53 & 40 & 39 & 37 \\
F. acuminatum strain UnB 356 & 27 & 47 & 57 & 57 \\
Galactose oxidase producer fungus & 8 & 26 & 46 & 83 \\
\hline
\end{tabular}

Table 4. Effect of the of culture media extracts $(100 \mu 1)$ on the mortality $(\%)$ of Artemia salina larvae.

\begin{tabular}{lccc}
\hline Fungi & $\begin{array}{c}\text { Markus' } \\
\text { medium } \\
\text { (G.oxidase) }\end{array}$ & $\begin{array}{c}\text { MMM } \\
\text { medium } \\
\text { (ADON) }\end{array}$ & $\begin{array}{c}\text { Richard's } \\
\text { medium } \\
\text { (Fusaric acid) }\end{array}$ \\
\hline F. graminearum strain UEL 2118 R & 5 & 11 & 14 \\
F. graminearum strain IAPAR 2218 & 17 & 19 & 11 \\
F. graminearum strain UnB 1269 & 25 & 13 & 20 \\
F. acuminatum strain UnB 356 & 12 & 13 & 11 \\
F. moniliforme & & & \\
$\quad$ var. subglutinans strain UnB 379 & 0 & 8 & 7 \\
Galactose oxidase producer fungus & 0 & 0 & 0 \\
\hline
\end{tabular}

\section{DISCUSSION}

The major purpose of this work was the comparison of five isolates of galactose oxidase-producing Fusarium with the GOPF, using different media. The comparison concerning growth rate (colony diameter) and pigmentation, as described by Booth (5), indicates that the compared fungal strains are distinct.

The analysis of the fungal extracts obtained from the various culture media, carried out according to the systematic procedure described by Kamimura (16), allowed the identification of some of the metabolites, mainly in rice and corn cultures. When other culture media were used, none of the studied metabolites was detected using the same conditions. Nevertheless, the literature reported production of fusaric acid by Giberella fujikuroi, F. heterosporum, F. moniliforme, F. moniliforme var. subglutinans and $F$. oxysporum (21) but there are no reports of its production by $F$. graminearum and $F$. acuminatum. Bacon et al. (4) demonstrated the production of this acid in 78 isolates of Fusarium moniliforme and also $F$. crookwellense, F. subglutinans, F. sambucinum, F. napiforme, F. heterosporum, $F$. oxysporum, F. solani and F. proliferatum. However, it is worth to note that the research was done in corn and not in Richard medium and in different conditions. It must be emphasised that none of the fungi mentioned above belongs to the Arthrosporiella section described by Booth (5).

Concerned to moniliformin, not detected in this study, similar data was reported by Marasas (21). This toxin was described in $F$. avenaceum, $F$. chlamydosporum, $F$. fusaroides, $F$. moniliforme, F. moniliforme var. subglutinans, F. oxysporum, F. verticillioides and Gibberella fujikuroi, but there is no report about its production in $F$. graminearum and $F$. acuminatum. Among these fungi, only F. fusarioides ( $=F$. chlamydosporum) belongs to the Arthrosporiella section described by Booth (5).

The production of DON and ADON is well documented, especially by $F$. graminearum, $F$. acuminatum and $F$. moniliforme (21). In this way, the designation of DON for the 
fungi grown in rice can be accepted (Table 1 and Fig.1). However, the tentative designation of ADON should be regarded with care due to the lower retention time of 3-ADON. However, the possibility of production of 15-ADON (23), diacetoxyscirpenol (16) or other metabolites can not be excluded. Comparatively, the amount of DON produced by GOPF is lower than that detected on the other fungi (Table 1).

The GLC profiles of the fungal metabolites produced in rice were ordered based on the similarities, considering the first and the last 10 min of the chromatogram (Fig. 1). A great similarity occurred between the complete profile of $F$. acuminatum strain 356 and $F$. graminearum strain $2118 \mathrm{R}$. GOPF and $F$. graminearum strain 1269 differed slightly in the first $10 \mathrm{~min}$, but increased the similarity in the remaining time, although they were different when compared with $F$. graminearum strain 2218. The profile of GOPF, when compared with $F$. graminearum, indicates that GOPF is similar to $F$. graminearum strain 1269 , but is distinct of $F$. acuminatum strain 356 or F. moniliforme var. subglutinans strain 379 .

In Fig. 2 the fungal growth in corn is compared. The chromatogram profiles showed the variation in the amounts of metabolites produced. The shouldered peaks difficulted the quantitative determination. In Fig. 2, the failure to detect metabolites on the galactose oxidase producing fungus calls the attention. This lack of metabolites deserves consideration, because the extract of GOPF, grown in corn, was toxic to Artemia salina larvae (Table 3). Literature describes growth of $F$. graminearum (8) and F. tricinctum (33) in corn, without production of trichothecenes, in spite of the toxicity to Artemia salina larvae. This is interesting, since data of Visconti et al. (32) indicate that Fusarium of the Sporotrichiella section produces mycotoxins. The Sporotrichiella section was described for the first time by Wollenweber (34) and includes $F$. sporotrichioides, F. poae, F. chlamydosporum and F. tricinctum. Later, this section was divided by Booth (5) in Sporotrichiella section, with $F$. tricinctum and $F$. poae and in Arthrosporiella section, with $F$. sporotrichioides, F. fusaroides, F. avenaceum, F. camptoceras, F. semitectum and F. semitectum var. majus. Based on the available data, GOPF may be considered unique, different from all those to which it was compared.

Another topic that deserves attention in Fig. 2 is the amount of metabolites (peaks of retention times of 6.00 and 6.35) produced by F. graminearum strain 2218 . This sample required a 10x attenuation. Nivalenol was detected by TLC in this sample, and also in $F$. graminearum strain 2118 and $F$. graminearum strain 1269 , indicating that this material is possibly nivalenol. Except for GOPF, chromatogram profiles (Fig. 2) were similar in the first five to seven min. Furthermore, Fig. 2 indicates that F. graminearum strain 1269 showed the highest number of peaks that coincide with the standards, confirming the presence of zearalenol, nivalenol and iso T-2. The extract of this fungus showed the higher toxicity to Artemia salina larvae (Table 3), followed by F. graminearum strain 2218, which exhibited larger peaks in the chromatogram. Both Fig. 1 and 2 indicate that peaks of similar retention times were also present in non inoculated commercial corn and rice.

The GLC analysis of Markus medium (galactose oxidase) exhibited peaks for $F$. moniliforme var. subglutinans strain 379 and $F$. graminearum strain $2118 \mathrm{R}$, with retention times of 6.00 and 6.35, which were compatible with FX and NIV, respectively. In this medium, the other fungi did not exhibit peaks under the conditions used. In MMM medium, the presence of ADON was observed $(0.16 \mu \mathrm{g} / \mathrm{g})$ only in $F$. graminearum strain 1269 . Finally, in Richard's medium nothing was detected.

This is the first report on the production of mycotoxins by Dactylium dendroides (GOPF). The extracts of Markus medium, MMM, and Richard's medium did not show any of the studied metabolites, nor toxic effects to Artemia salina larvae (Table 4). This data, in addition to the other aspects, distinguish GOPF $\Delta$ from Fusarium spp. studied here. Nevertheless, this is the first time that an evidence of DON production by GOPF is reported. According to Marasas et al. (21), F. acuminatum, F. culmorum, $F$. graminearum, $F$. moniliforme, $F$. nivale, Gibberella zeae and F. sporotrichioides, only the last belonging to the Arthrosporiella section, are DON producing fungi. Considering that the time for growth in rice is 21 days, which is also adequate for production of trichothecenes, and that toxicity of the extracts to larvae of Artemia salina was demonstrated, more studies with these fungi in the future are recommended.

Based on the similarity between the conidia and conidiophores of GOPF and F. chlamydosporum mentioned by Ögel (26), complementary testing for chlamydosporol, a toxic metabolite produced by $F$. chlamydosporum (29), and for visoltricine produced by F. tricinctum (33), should be done to study further similarities between these fungi.

\section{RESUMO}

\section{Produção de micotoxinas por Fusarium produtor de galactose oxidase usando diferentes meios de cultivo}

O isolado original do fungo produtor de galactose oxidase Dactylium dendroides e outros cinco isolados de Fusarium, também produtores de galactose oxidase, foram cultivados em diferentes meios e condições, com o objetivo de estudar a produção de onze micotoxinas características do gênero Fusarium: moniliformina, ácido fusárico, deoxinivalenol, fusarenona- X, nivalenol, 3-acetildeoxinivalenol, neosolaniol, zearalenol, zearalenona, acetil T-2 e iso T-2. A toxicidade dos extratos obtidos nos diferentes cultivos foi testada em larvas de Artemia salina.

Palavras-chave: Dactylium dendroides, Fusarium, galactose oxidase, micotoxinas 


\section{REFERENCES}

1. Aisaka, K.; Terada, O. Production of galactose oxidase by Gibberella fujikuroi. Agric. Biol. Chem., 45: 2311-2316, 1981.

2. Amaral, D.; Kelly-Falcoz, F.; Horecker, B. L. Galactose oxidase of Polyporus circinatus.In : S.P. Colowick \& N.O. Kaplan (eds), Methods in Enzymology. 1966, pp.87-92.

3. Avigad, G.; Amaral, D.; Asensio, C.; Horecker, B. L. The D-galactose oxidase of Polyporus circinatus. J. Biol. Chem., 237: 2736-2743, 1962.

4. Bacon, C.W.; Porter, J. K.; Norred, W. P.; Leslie, J. F. Production of Fusaric Acid by Fusarium Species. Appl. Environ. Microbiol., 62: 4039-4043, 1996.

5. Booth, C. Fusarium - Laboratory Guide to the identification of the major species. Commonwealth Agricultural Bureaux, Kew, Surrey, England, 1977.

6. Buglova, T.T.; Kirilenko, T.S.; Zakharova, Y, I.; Yunitskaya, V.A. Description of Fusarium graminearum IMV-F 1060 a producer of galactose oxidase. Mikol. Fitopatol., 16: 503-508, 1962.

7. Cole, R. J. Modern Methods in the analysis and Structural Elucidation of Mycotoxins. London.: Academic Press.,1986.

8. Combrinck, S.; Gelderblom, W.C.: Spies, H.S.; Burger, B.V.; Thiel, P.G.; Marasas, W.F. Isolation of trichothecin from corn cultures of Fusarium graminearum MRC 1125. Appl. Environ. Microbiol., 54:1700-17002, 1988.

9. Cooper, J.A.D.; Smith, W.; Bacila, M. ; Medina, H. Galactose oxidase from Polyporus circinatus, Fr. J. Biol. Chem., 234: 445-448, 1958.

10. Davis, D. Carbohydrate specificity for Fusaric acid synthesis. Phytopathology. 60: 111-113, 1970.

11. Dias, D.; Kemmelmeier, C. Ocorrência de Galactose oxidase em Fusarium graminearum. Rev. Microbiol., 18: 276-278, 1987.

12. Eppley, R.M. Sensivity of Brine Shrimp (Artemia salina) to trichothecenes. J. Assoc. Off. Anal. Chem., 57: 618-620, 1974.

13. Gancedo, J.M.; Gancedo, C.; Asensio, C. Widespread occurrence of galactose oxidase and glucose oxidase in fungi. Arch. Biochem. Biophys., 119: 588-590, 1967.

14. Gimeno, A.; Ramos A.J.; Hernández, H. Estudio de la producción de deoxinivalenol (DON) por Fusarium graminearum. Rev. Iberoam. Micol., 9: 55-57, 1990.

15. Harwig, J.; Scott, P. M. Brine Shrimp (Artemia salina L.) larvae as a screening system for fungal toxins. Appl. Microbiol., 21: 1011- 1016, 1971.

16. Kamimura, H.; Nishijima, M.; Yasuda, K.; Saito, K.; Ibe. A.; Nagayama, T.;Ushiyama, H.; Naoi, Y. Simultaneous detection of several Fusarium mycotoxins in cereals, grains and foodstuffs. J. Assoc. Off. Anal. Chem., 64: 1067-1073, 1981.

17. Kemmelmeier, C.; Zancan, G.T. Taxonomy of galactose oxidase producer fungi strain. Arq. Biol. Tecnol., 19: 25-30, 1976.

18. Kemmelmeier, C. ; Zancan, G.T. Studies of the taxonomy of a mold producing galactose oxidase. Arq. Biol. Tecnol., 21: 75-85,1978.
19. Kemmelmeier, C.; Zancan, G. T. Chemical and immunological properties of galactoglucomannans from Dactylium dendroides. Exp. Mycol., 5: 339348, 1981.

20. Kemmelmeier, C.; Zancan, G.T. Serological differentiation of the galactose oxidase producer mold from Dactylium dendroides. Arq. Biol. Tecnol., 26: 403-408, 1983.

21. Marasas, W.F.O.; Nelson, P.E; Toussoun, T. A. Toxigenic Fusarium species. Identity and Mycotoxicology. The Pennsylvania State University Press. U.S.A. 1984, 328p.

22. Markus, Z.; Miller, G.; Avigad, G. Effect of culture conditions on the production of galactose-oxidase by Dactylium dendroides. Appl. Microbiol., 13: 686-693,1965.

23. Miller, J.D.; Taylor, A.; Greenhalgh, R. Production of deoxynivalenol and relates compounds in liquid culture by Fusarium graminearum. Can. Jour. Microbiol., 29: 1171-1178. 1983.

24. Mirocha, C.J.; Abbas, H.K.; Vesonder, R.F. Absence of Trichothecenes in toxigenic isolates of Fusarium moniliforme. Appl. Environ. Microbiol., 56: 520-525, 1990.

25. Nobles, M. K.; Madhosingh, C. Dactylium dendroides (Bull) Fr. misnamed as Polyporus circinatus Fr. Biochem. Biophys. Res. Commun., 12: 146147,1963 .

26. Ögel, Z. B.; Brayford, D.; McPherson, M. J. Cellulose-triggered sporulation in the galactose oxidase-producing fungus Cladobotryum (Dactylium) dendroides NRRL 2903 and its re-identification as a species of Fusarium. Mycol. Res., 98: 474-480, 1994.

27. Pereira, I. M.; Zancan, G.T. Restriction enzyme fragment patterns of mtDNA from a galactose oxidase-producing mold. Brazilian J. Med. Biol. Res., 26:1047-1055, 1993.

28. Rabie, J. C.; Lübben, A.; Louv, A. I.; Rathbone, E.B.; Steyn, P. S.; Vleggaar, R Moniliformin, a mycotoxin from Fusarium fusarioides. J. Agric. Food Chem., 26: 375-379,1978.

29. Savard, M.E.; Miller, J.D.; Salleh, B.; Strange, R.N. Chlamydosporol, a new metabolite from Fusarium chlamydosporum. Mycophathologia. 110: 177-181, 1990.

30. Silva, N.S. Co-produção de metabólitos secundários (micotoxinas) em isolados de Fusarium graminearum sob condições definidas de cultivo. Maringá, 1993, 74p (Dissertação de Mestrado. Departamento de Bioquímica. UEM).

31. Vasavada, A B.; Hsieh, D. P. H. Production of 3-acetyldeoxynivalenol by Fusarium graminearum R 2118 in submerged cultures. Appl. Microbiol. Biotechnol., 26: 517-521, 1987.

32. Visconti, A. ; Minervini, F.; Solfrizzo, M.; Bottalico, C.; Lucivero, G. Toxicity of some Fusarium section Sporotrichiella strains in relation to mycotoxin production. Appl. Environ. Microbiol. 58: 769-772, 1992.

33. Visconti. A. ; Solfrizzo, M. Isolation, Characterization, and Biological activity of Visoltricin, a novel metabolite of Fusarium tricinctum. J. Agric. Food Chem., 42: 195-199, 1994.

34. Wollenweber, H.W.; Reinking, O. A. Die Fusarien, ihre Beschreibung, Schadwirkung und Bekämpfung. Paul Parey, Berlin. 1935. 